\title{
Effect of Pipeline External Geometry on Local Scour and Self-Burial Time Scales in Current
}

\author{
M. Damroudi ${ }^{1}$, K. Esmaili ${ }^{1,2 \dagger}$ and S. H. Rajaei ${ }^{3}$ \\ ${ }^{1}$ Department of Civil Engineering, Najafabad Branch, Islamic Azad University, Najafabad, Isfahan, \\ 8514143131, Iran \\ ${ }^{2}$ Department of Water, Science and Engineering, Ferdowsi University of Mashhad, Mashhad, Khorasan \\ Razavi ,9177948974, Iran \\ ${ }^{3}$ Khorasan Razavi Agriculture and Natural Resources Research and Education Center, Mashhad, Khorasan \\ Razavi ,6641691659, Iran
}

$\dagger$ Corresponding Author Email: Esmaili@um.ac.ir

(Received January 27, 2020; accepted June 8, 2020)

\begin{abstract}
Changes in the external geometry of the pipeline laid on the erodible beds may affect the local scour around pipe. If the scouring process below the pipe is accelerated, the pipe buries on the bed (known as self-burial of the pipe) and can be used as a cheap alternative to mechanical trench digging. In this study, the effect of changes in the external geometry of the pipe in order to accelerate the scouring and self-burial pipe processes by spoiler and piggy back under unidirectional flow on the erodible bed is investigated. The results showed that the time scale of self-burial process is less than that of the scouring process. At the angles of 180, 135 and $225^{\circ}$, the Spoiler and piggy back reduced the time scale of self-burial and scouring process and increased the scour and self-burial depths, as well as the lee erosion length as compared with the simple pipe. At angles of 90 and $270^{\circ}$, the scale time of scour and self-burial processes are increased, the scour and self-burial depths and the lee erosion length are decreased as compared with the simple pipe. It can be concluded that the performance of piggy back is similar to the spoiler, therefore, they are of similar application and could be a suitable alternative for the spoiler.
\end{abstract}

Keywords: Local scour; Pipeline; Spoiler; Piggy back; Self-Burial.

\section{NOMENCLATURE}

$\begin{array}{ll}B & \text { flume width } \\ D & \text { pipe diameter } \\ d^{*} S & \text { self-burial depth } \\ d^{*} S e & \text { equilibrium self-burial depth } \\ d_{50} & \text { average sediment grain size } \\ d_{S} & \text { scour depth } \\ d_{S e} & \text { equilibrium scour depth } \\ F_{p} & \text { shape of the spoiler and Piggy back } \\ & \text { parameter } \\ g & \text { gravitational acceleration } \\ h & \text { height of piggy back and spoiler } \\ L^{*} S & \text { lee erosion length of self-burial } \\ L S & \text { lee erosion length of scour } \\ P & \text { empirical coefficient } \\ Q & \text { flow discharge } \\ R e & \text { Reynolds number }\end{array}$

\section{INTRODUCTION}

The passage of pipelines through the erodible bed of the sea and the rivers may cause changes in the

\begin{tabular}{|c|c|}
\hline & relative density of sediment \\
\hline$S_{F}$ & energy line slope \\
\hline$T$ & scour time scale \\
\hline$T^{*}$ & self-burial time scale \\
\hline$T_{f}$ & time scale related to exponent $P$ \\
\hline$V$ & flow velocity \\
\hline$V *^{*} C$ & critical bed shear velocity \\
\hline & flow depth \\
\hline$\alpha$ & angle of piggy back and spoiler \\
\hline$\theta$ & shields parameter \\
\hline$\rho_{s}$ & density of sediment \\
\hline$\rho_{w}$ & density of water \\
\hline$\sigma_{g}$ & geometric standard deviation \\
\hline & kinematic viscosity of water \\
\hline
\end{tabular}

flow pattern around the pipelines, creating local scour around the pipelines. The pipeline laid on the erodible beds is capable of self-burial process due to local scouring Chiew (1990). However, the time 
and depth of self-burial of the pipe is not suitable for practical purposes (Hulsbergen, 1986).

If the self-burial process of a pipeline is accelerated and the maximum self-burial depth is increased, it can be used as a cheap alternative to mechanical trench digging. One of the approaches to accelerate the scour below the pipe and self-burial of the pipe is to use the spoiler. Spoiler is a plate that added on the main pipe. Duo to pass the telecommunication cables through the sea beds or riverbeds used to piggy back. Piggy back is a small diameter pipe added on the main pipe. The spoiler and piggy back may change the external geometry of the pipe which can be affect the scour and self-burial processes.

(Hulsbergen, 1984 \& 1986; Hulsbergen \& Bijker 1989; Chiew 1990; Yang et al. 2012) have stated that the spoiler can accelerate the self-burial process of a pipeline Bearman \& Zdravkovich (1987) observed three flow separation zones, in upstream and downstream of the pipe. Sumer \& Fredsøe (1997) provided a complete review on the flow regimes around a cylinder under steady state for different Reynolds numbers. (Cheng \& Chiew 2003; Zhao \& Wang 2009; Zeitoun et al. 2010; Branković et al. 2010), showed that attaching a Circular piggy back or Spoiler on top of the pipe, would increase the drag force and decrease the lift force compared to a simple pipeline, which can be effective in pipeline stability. Shan et al. (2015) concluded that the Froude number and spoiler height are effective on scour depth below the pipe. Draper et al. (2015) found experimentally that the self-burial of inflexible pipe is more than flexible one. (Zhao \& Cheng 2007; Zang et al. 2013), concluded that vortex shedding around Circular piggy back depends on the ratio of initial burial to pipe diameter $(G / D)$ and the ratio of piggy back distance from pipe to pipe diameter $(e / D)$. Oner (2016) stated that the installation of the spoiler would create a large flow separation zone in upstream and downstream of the pipe. Lee et al. (2019) studied the effect of spoiler on the flow, vortex and pressure around the pipe using numerical model (Navier Stokes). Zhang and Shi (2016) presented a new method based on computational fluid dynamics for scouring of submerged pipeline. Abbasi et al. (2018) studied the effect of spoiler and flow angle on scouring beneath the pipeline using FLOW-3D model. Zhao et al. (2018) numerically and experimentally studied the effect of Circular piggy back distance from the main pipeline to pipe diameter $(e / D)$ on the scour below the pipe and the vortex shedding around it under unidirectional.

The relationship between the scour time scale and the scour rate was first presented Whitehouse (1998) (Eq. 1):

$$
d s=d s_{e}\left\{1-\exp \left[-\left(t / T_{P}\right)^{P}\right]\right\}
$$

where, $P$ is an empirical coefficient, $T_{f}$ is the time scale related to exponent $P, d_{S}$ is the scour depth in time $t, t$ is the time, $d_{s e}$ is the equilibrium scour depth. Fredsøe and Deigaard (1992) calculated the value $P$ equal to 1 and presented the following equation:

$d s=d s_{e}\left\{1-\exp \left[-\left(t / T_{f}\right)\right]\right\}$

where, $T_{f}$ is the time scale of the scouring process normalized as follows:

$T_{f}^{*}=\frac{\left[g-(\mathrm{s}-1) \mathrm{d}_{50}{ }^{3}\right]^{0.5}}{D^{2}} T_{f}$

where, $D$ is the pipe diameter, $s$ is the relative density of sediment, $d_{50}$ is average sediment grain size, $g$ is the gravity acceleration and $T_{f}^{*}$ is the nondimensional time scale of the scour process determined as follows:

$T_{f}^{*}=\theta^{-5 / 3} / 50$

where, $\theta$ is Shields parameter. By examining certain values of $P$, Zhang et al. (2017) proposed the value of 0.6 and developed Eq. 5 as follows:

$d s=d s_{e}\left\{1-\exp \left[-\left(t / T_{g}\right)^{0.6}\right]\right\}$

where, $T_{g}$ is the time scale of the scour process for the exponent of 0.6 obtained from the Eq. 6 (Zhang et al. 2017):

$$
T_{g}=1.29 T_{f}
$$

According to Fig. 1, the value of $T_{f}$ is also calculated based on the experimental results (Fredsøe and Deigaard 1992).

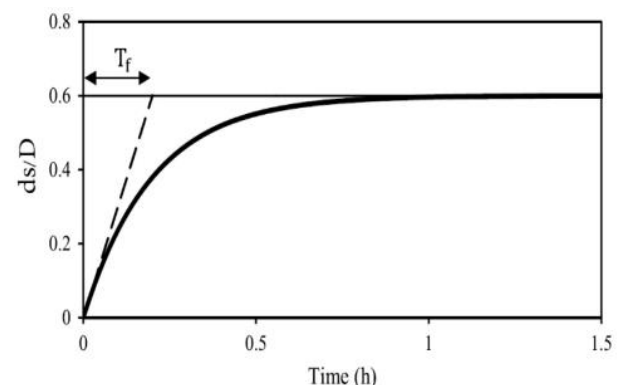

Fig. 1. Determination of scour time scale by slope method (Fredsøe and Deigaard 1992).

In general, the existence of experimental results for the equilibrium self-burial and scour depths and the prediction formulas for the scour time scale show that, until now, less attention has been paid to the effect of external geometry of the pipe on the selfburial and scour times scales. There is also no study on the effect of piggy back on self-burial pipe. Therefore, in the present study, the effect of the external geometry of the pipe on the self-burial and scour time scales are investigated.

\section{Material ANd Methods}

\subsection{Dimensional Analysis}

The parameters influencing the self-burial depth of 


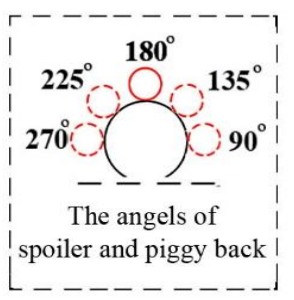

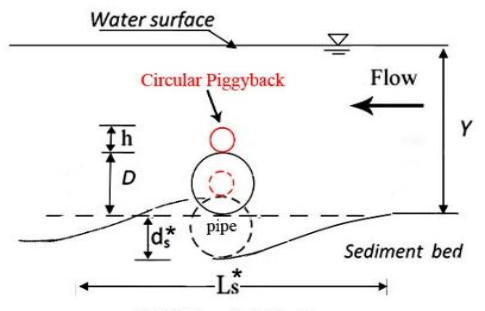

Self-Burial Bed

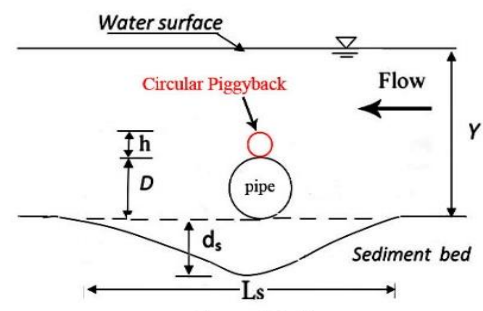

Scour Bed

Fig. 2. Schematic of experimental simulation.

a pipe $\left(d^{*} s\right)($ Eq. 7$)$ and the scour depth below a pipe $\left(d_{s}\right)($ Eq. 8) can be presented as follows:

$$
d_{S}^{*}=f_{1}\left(t, T^{*}, L_{S}^{*}, D, h, \alpha, F_{P}, \mathrm{~B}, \mathrm{~d}_{50}, \mathrm{y}, \mathrm{v}, \mathrm{g}, v, \rho_{S}, \rho_{W}\right)
$$

$d_{S}=f_{1}\left(t, T, L_{S}, D, h, \alpha, F_{P}, \mathrm{~B}, \mathrm{~d}_{50}, \mathrm{y}, \mathrm{v}, \mathrm{g}, v, \rho_{S}, \rho_{W}\right)$

where, $\mathrm{t}$ is the time, $d^{*}{ }_{S}$ is the self-burial depth in time $t, T^{*}$ is the self-burial time scale, $L^{*} S$ is the lee erosion length self-burial pipe in time $t, d_{S}$ is the scour depth in time $t, T$ is the scour time scale, $L_{S}$ is the lee erosion length in time $t, D$ is the pipe diameter, $h$ is the piggy back and Spoiler height, $\alpha$ is the angle of Spoiler and piggy back, $F_{p}$ is the shape of the spoiler and piggy back parameter, $S_{f}$ is the Energy line slope, $B$ flume width, $\rho_{w}$ density of water, $\rho_{\mathrm{s}}$ density of sediment, $V$ flow velocity, $y$ flow depth, $v$ kinematic viscosity of water $\left(=10^{-6}\right.$ $\left.\mathrm{m}^{2} / \mathrm{s}\right), g$ gravitational acceleration and $d_{50}$ is the average sediment grain size of the bed material. In this study, due to constant flow conditions, particle size and flume width were ignored. In addition, the influence of $v$ is considered negligible under a fully developed turbulent flow over a rough bed (Dey \& Barbhuiya 2004). Applying the Buckingham $\pi$ theorem the non-dimensional parameters were obtained as Eqs. 9 and 10.

$$
\begin{aligned}
& \frac{d_{S}^{*}}{D}=f_{1}\left(\frac{t}{T^{*}}, \frac{L_{S}^{*}}{D}, \frac{h}{D}, \alpha, F_{P}\right) \\
& \frac{d_{S}}{D}=f_{1}\left(\frac{t}{T}, \frac{L_{S}}{D}, \frac{h}{D}, \alpha, F_{P}\right)
\end{aligned}
$$

Figure 2 shows the parameters affecting the scouring and self-burial of the pipe.

\subsection{Experimental Set-Up}

All experiments were carried out in the Hydraulic Laboratory of the Khorasan Razavi Agricultural Research and Training Center and in a laboratory flume with a length of $11 \mathrm{~m}$ and $50 \mathrm{~cm}$ in width with thick glass walls (Fig. 3). The pipe diameter was selected based on the flume dimensions equal to $3 \mathrm{~cm}$ (hollow) and the material was galvanized iron. Also, spoiler and piggy back are made of 1 $\mathrm{mm}$ galvanized sheet. In order to the median particle size of the bed material $\left(d_{50}\right)$ to have no effect on the scour depth, the median particle size of the sediment must be greater than or equal to 0.7 $\mathrm{mm}\left(d_{50} \geq 0.7 \mathrm{~mm}\right)$ (Breusers \& Raudkivi 1991). In the present study, a non-cohesive sand with a median particle size of $0.7 \mathrm{~mm}$ and a geometric standard deviation of $\sigma_{g}=1.2$ was selected.

In order to achieve a fully developed flow, a length of $4 \mathrm{~m}$ from the beginning of the flume was considered for doing the experiments. To reach the threshold conditions, the ratio of $V / V_{C}$ was chosen as 0.9 ( $V_{C}$ is the critical velocity).

The critical velocity $V c$ was determined from Eq. 11 (Melville \& Sutherland 1988).

$\frac{V_{C}}{V_{C}^{*}}=5.75 \log \left(5.53 \frac{y}{d_{50}}\right)$

where, $V{ }^{*} C$ is the critical shear velocity $(\mathrm{m} / \mathrm{s})$ which can be calculated using the following relationship (Melville 1997):

$V_{* C}=0.0115+0.125 d_{50}^{1.4} \quad 0.1 \mathrm{~mm} \leq d_{50} \leq 1 \mathrm{~mm}$

In all experiments, the unidirectional flow was adjusted as uniform and subcritical $(F r=0.2)$ with

$Q=28 \mathrm{~L} / \mathrm{s}, y=0.21 \mathrm{~m}, v=0.27 \mathrm{~m} / \mathrm{s}$ and $V_{c}=0.3$ $\mathrm{m} / \mathrm{s}$. Figure 4 illustrates the bed profiles in some experiments of this study.
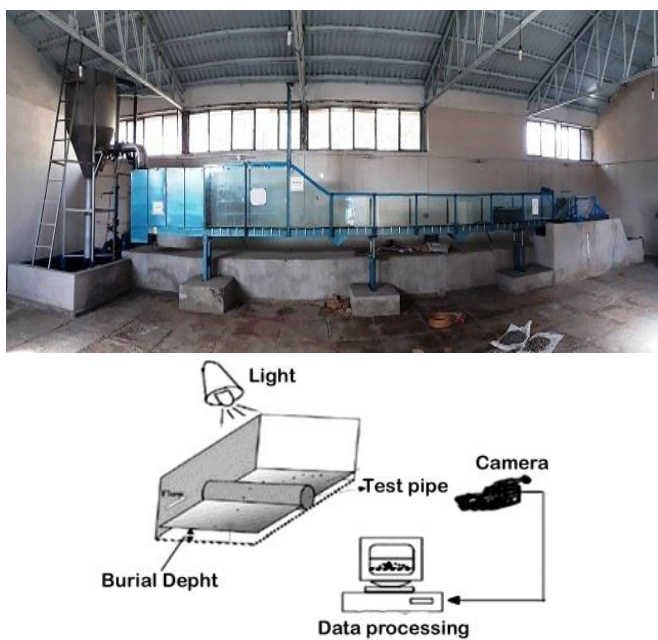

Fig. 3. Sketch of the experimental set-up.

Detailed hydraulic and sediment transport tests were conducted to study the structure of threedimensional flow, turbulence, and bed scour formation one coarse sediments (Melville 1984) with median particle sizes $d_{50}$ of $0.7 \mathrm{~mm}$, were 


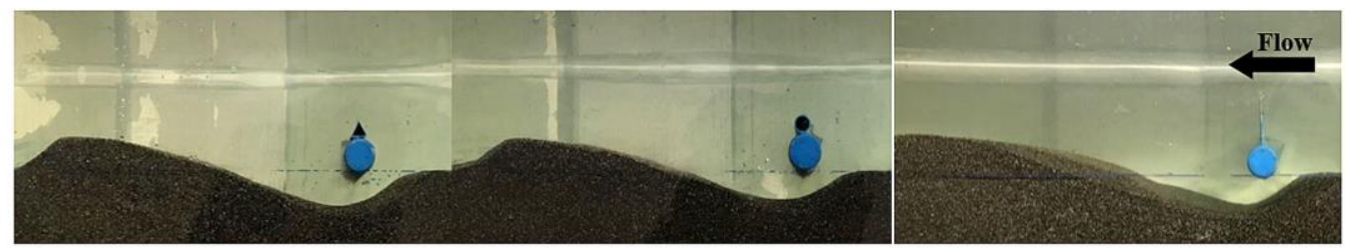

Profiles of the scour bed

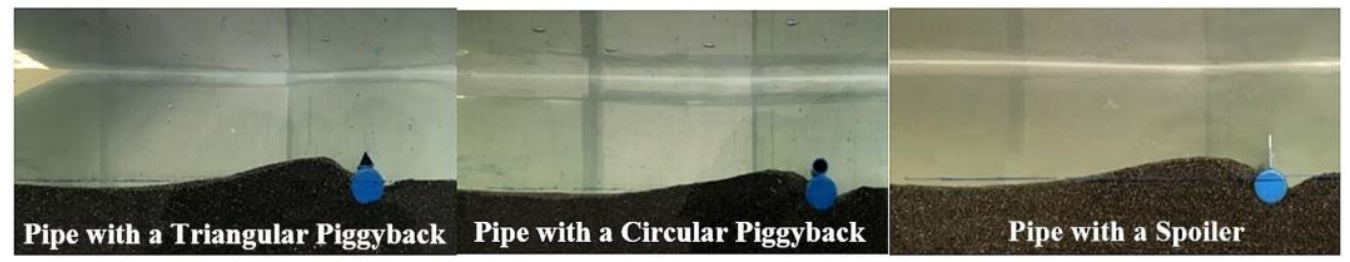

Profiles of the self-burial bed

Fig. 4. Some Image of the experiments in the present study (angle: $180^{\circ}$ ).

selected for bed erosion tests. The standard deviation of particle sizes was less than 1.3, indicating that the tested particles were statistically uniform. The sediment transport experiments were carried out in clear-water conditions (i.e., $V_{a v e} / V_{c} \leq$ 1). The critical threshold velocity was calculated based on assuming a logarithmic velocity profile [i.e., $\left.V_{c} / V_{*_{c}}=5.75 \log \left(5.53 y d_{50}\right)\right]$ and shear velocities were determined from approximated formula based on the Shields diagram (Melville 1997). Every clear-water scour test was commenced from an initial flat bed and continued until the equilibrium stage was achieved. Based on experimental test condition (equilibrium was reached between 4 and 6 hours after beginning the tests (Guan et al. 2014 and 2015; Salehi et al. 2019). Based on these studies, it is assumed the eroded bed were stabilized. Besides, the equilibrium time of scour bed and self-burial were tested for some incidental experimental tests and the equilibrium condition were stabilized between 3 and 4 hours. It seems due to this period the turbulent flow through pipe line with different types of spoiler reach stable condition.

The scour hole profiles were measure by point gage at the upstream and downstream of the pipeline and the profiles under the pipeline were measured by processing captured photo at the longitudinal section at the upstream and downstream the experimental models.

\subsection{Numerical Model}

To investigate the flow condition through the pipeline with spoilers, the numerical model was employed due the different condition (self-burial and scour bed). To validation between numerical model and experimental model, the vertical velocity profile was compared to illustrate the accuracy the numerical model. In this study, mesh grids were implemented in Ansys Meshing tool and a structured quadratic-dominant mesh with 42400 elements and 43150 nodes were constructed. The mesh sensitivity analysis was done by changing the number of nodes and elements and comparing the developed velocity profile in the upstream side of pipeline. The mesh was refined near the wall surfaces, pipeline length and $5 \mathrm{~m}$ above and below the weir crest to enhance the accuracy of the numerical solution near the surface profile. The average constant velocity inlet was defined at the upstream boundary condition (Xmin) for both air and water phases. Furthermore, to minimize the air domain effect, the air depth must be at least onethird of the water depth (Salaheldin and Imran 2004). In this regard, the air domain depth was set to half of the maximum upstream water depth and subsequently, the upper boundary was set to as symmetry (Zmax). The bed surface and the pipeline profile surface were considered as wall boundary with no-slip boundary condition (Zmin). For adjusting a constant tailwater depth downstream, a wall boundary condition was defined in downstream boundary (Xmax). For the initial condition $(\mathrm{F}=1)$, the upstream water domain depth was set to as the weir elevation. The flow rate at the outlet boundary and also the free surface elevation at the inlet boundary were monitored during the simulation process. It was found that with 30 seconds simulation, the solution becomes fully converged and steady-state conditions were achieved. The upstream boundary length from the weir was $6 \mathrm{~m}$ and monitoring of the temporal variations of the water surface elevation at various stations downstream of the inlet boundary showed that this length is sufficient enough for an undisturbed approach flow to be established. Figure 5 show the boundary condition of pipeline in the numerical models.

\subsection{Numerical Model Validation}

In order to validation the numerical model, after finding the suitable mesh size (see previous section), the water surface and velocity profile were employed to comparison. The experimental profile was depicted from velocity measurement along the longitudinal section due to one experimental test by applying the Pitot tube. Figure 6 show the experimental and numerical velocity profile. As it can be seen, the velocity profiles in both models has acceptable result. It seems, using the numerical model can illustrated the flow configuration along the experimental tests. 


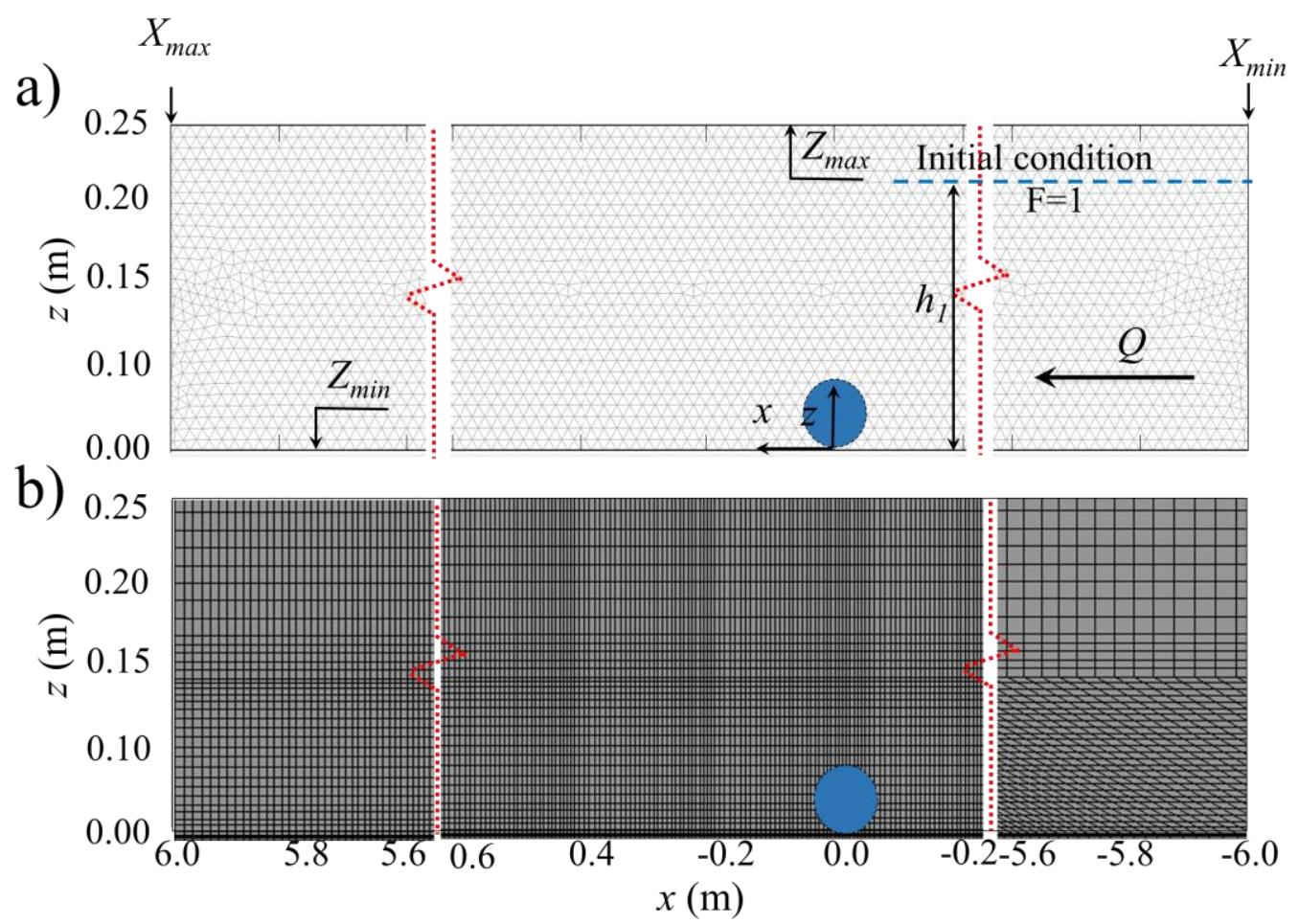

Fig. 5. Mesh properties and initial condition of the numerical model, a) Triangular mesh; b) rectangular mesh.
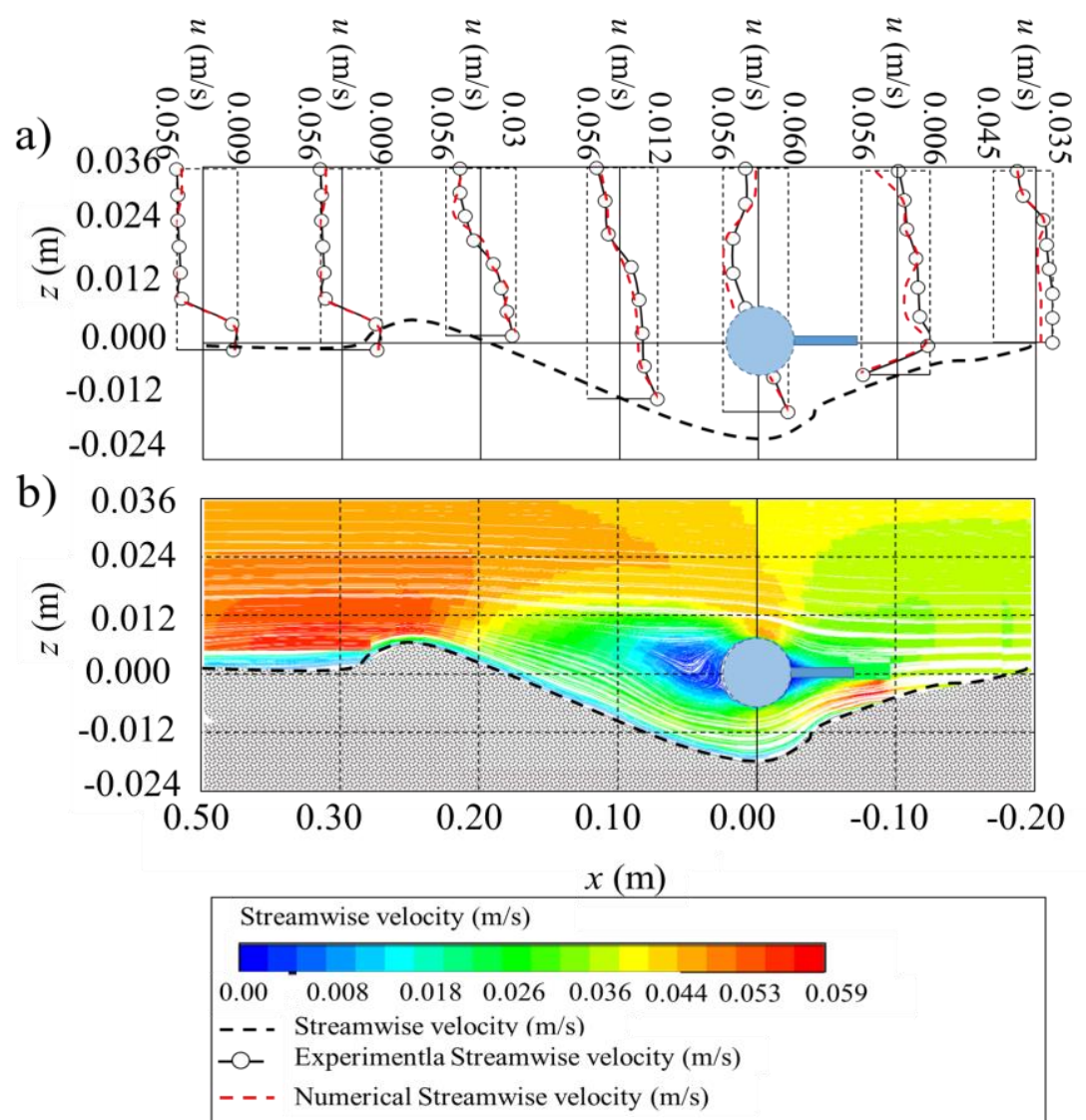

Fig. 6. Validation of numerical model a) Comparsion between numerical and experimental velocity profiles; b) Contour plot os streamwise velocity ( $S p o i l e r, ~ a=90^{\circ}, h / D=1$ ). 

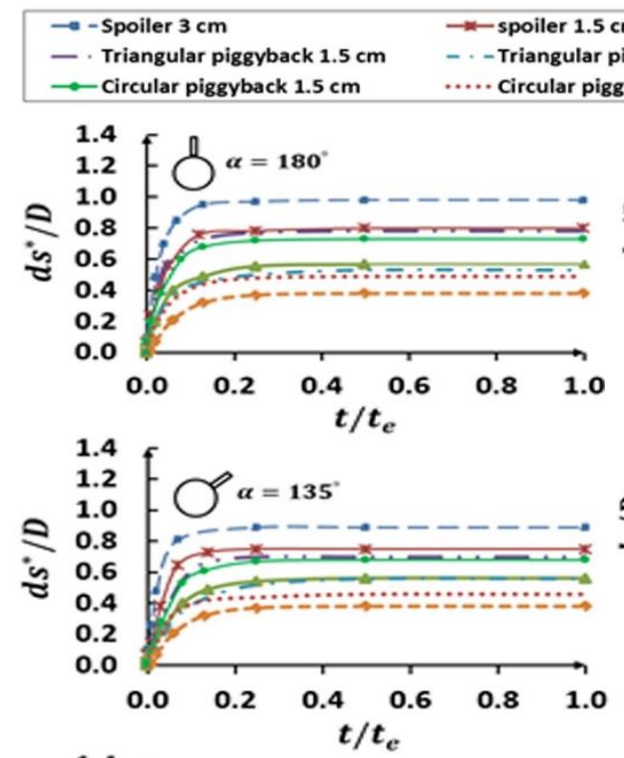

\begin{tabular}{ll}
$\mathrm{cm}$ & - spoiler $0.75 \mathrm{~cm}$ \\
piggyback $0.75 \mathrm{~cm}$ & -- -simple pipe \\
\hline gyback $0.75 \mathrm{~cm}$ &
\end{tabular}
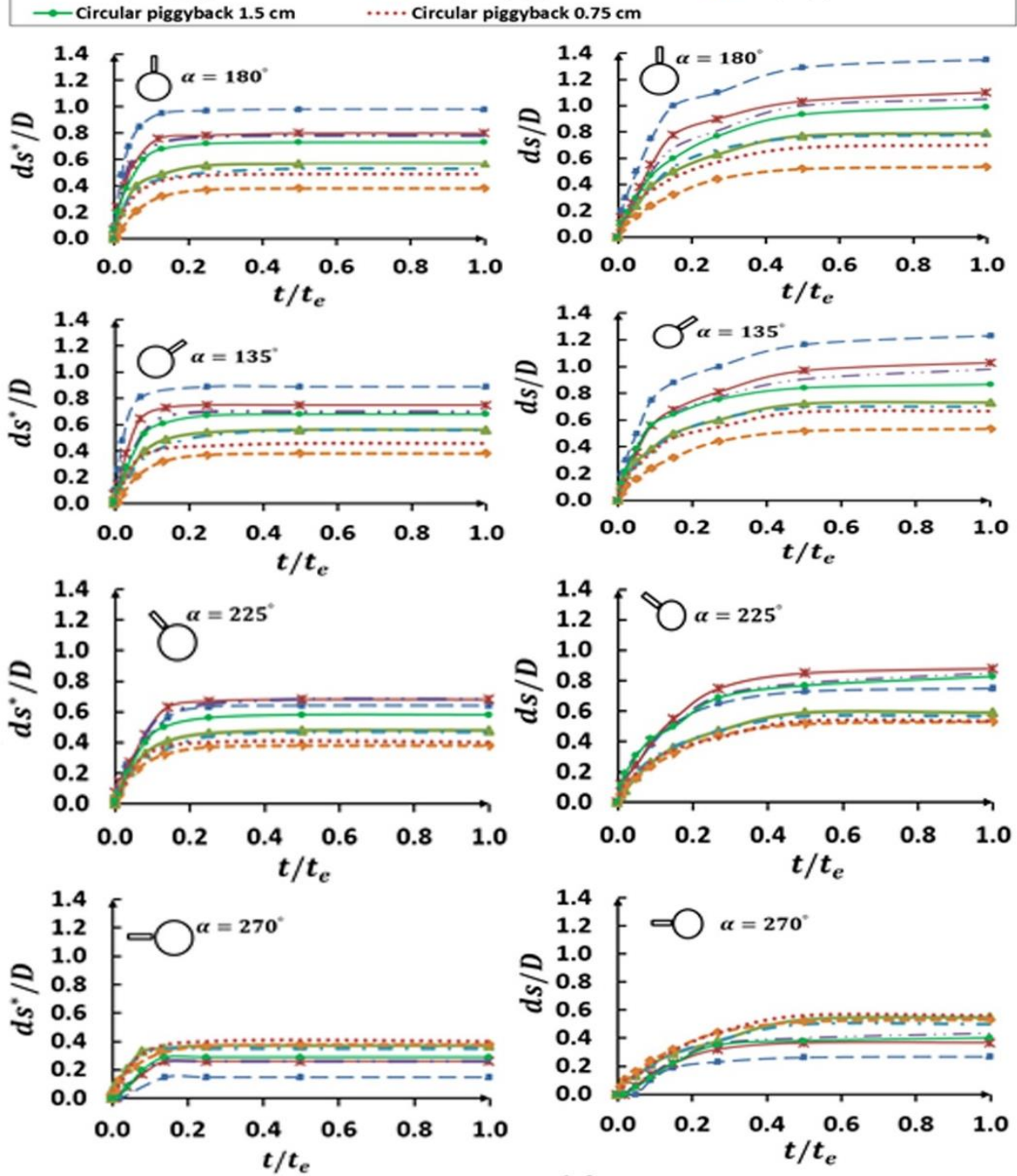

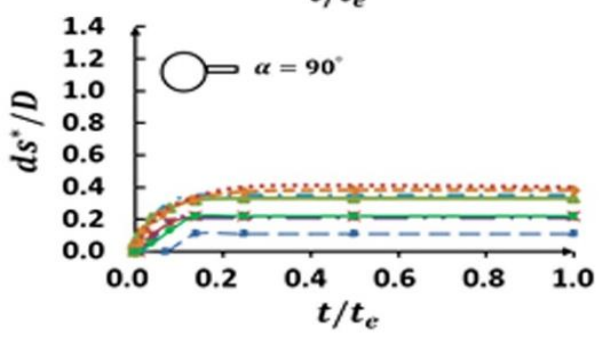

a) Self-burial

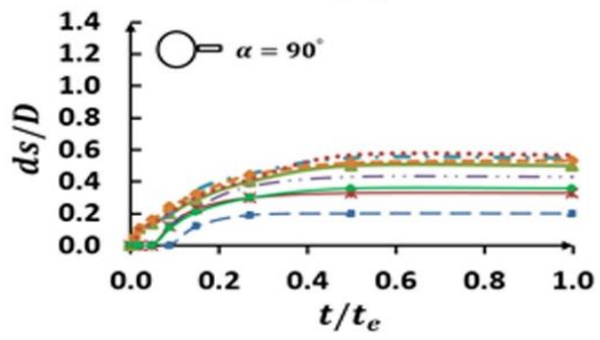

b) Scour

Fig. 7. Non-dimensional equilibrium time of the bed.

\section{RESULTS AND DISCUSSION}

3.1 Effect of Spoiler and Piggy back on Scouring and Self-Burial depths and Times

To determine the amount of $T$ and $T^{*}$, the amount of non-dimensional scour and self-burial depths were plotted versus non-dimensional times (Fig. 7).

As can be seen, the temporal variations of the scour depth follow a semi-logarithmic equation, such that in the first moments of the experiment, the scour depth expansion is faster and the line slope is steeper and then the scour depth expansion is gradually decreased and the line slope becomes slower. The temporal variations of self-burial depth like the scouring process, follow a semi-logarithmic equation, such that in the first moments of the experiments, the self-burial depth expansion is fast and has a steep line slope and slows down over a short time period. As shown in Fig. 7, at an angles of 180 and $135^{\circ}$, with increasing the spoiler and piggy back heights ( $h=D$ and $h=D / 2)$, the cross- 
M. Damroudi et al. / JAFM, Vol. 14, No. 1, pp. 103-115, 2021.

Table 1 Experimental results

\begin{tabular}{|c|c|c|c|c|c|c|c|c|c|c|}
\hline \multirow[t]{2}{*}{$F_{p}$} & \multirow{2}{*}{$\begin{array}{l}\text { Abbre } \\
\text { viate }\end{array}$} & \multirow[t]{2}{*}{$h / D$} & \multirow[t]{2}{*}{ Angle } & \multirow[t]{2}{*}{ Tests } & \multirow{2}{*}{$\begin{array}{c}d_{50} \\
(\mathrm{~mm})\end{array}$} & \multicolumn{2}{|c|}{ Result of Scour } & \multirow[t]{2}{*}{ Tests } & \multicolumn{2}{|c|}{$\begin{array}{l}\text { Result of Self- } \\
\text { Burial }\end{array}$} \\
\hline & & & & & & $d s / \mathrm{D}$ & $\mathrm{t} / \mathrm{T}$ & & $d s * / D$ & $t / T^{*}$ \\
\hline \multirow{3}{*}{ Spoiler } & \multirow{3}{*}{ TS } & 1 & 180 & 1 & 0.7 & 1.35 & 6.67 & 37 & 0.98 & 25 \\
\hline & & 0.5 & 180 & 2 & 0.7 & 1.10 & 5.88 & 38 & 0.80 & 20 \\
\hline & & 0.25 & 180 & 3 & 0.7 & 0.79 & 4.35 & 39 & 0.57 & 11 \\
\hline \multirow{2}{*}{$\begin{array}{l}\text { Triangular } \\
\text { piggy back }\end{array}$} & \multirow{2}{*}{$\mathrm{TP}$} & 0.5 & 180 & 4 & 0.7 & 1.05 & 5.26 & 40 & 0.78 & 20 \\
\hline & & 0.25 & 180 & 5 & 0.7 & 0.78 & 4.76 & 41 & 0.53 & 11 \\
\hline \multirow{2}{*}{$\begin{array}{c}\text { Circular } \\
\text { Piggy back }\end{array}$} & \multirow{2}{*}{$\mathrm{CP}$} & 0.5 & 180 & 6 & 0.7 & 0.99 & 4.55 & 42 & 0.73 & 18.2 \\
\hline & & 0.25 & 180 & 7 & 0.7 & 0.70 & 4.17 & 43 & 0.49 & 11 \\
\hline \multirow{3}{*}{ Spoiler } & \multirow{3}{*}{ TS } & 1 & 135 & 8 & 0.7 & 1.23 & 6.25 & 44 & 0.89 & 20 \\
\hline & & 0.5 & 135 & 9 & 0.7 & 1.03 & 5.56 & 45 & 0.75 & 14.3 \\
\hline & & 0.25 & 135 & 10 & 0.7 & 0.73 & 4.35 & 46 & 0.56 & 9.1 \\
\hline \multirow{2}{*}{$\begin{array}{l}\text { Triangular } \\
\text { piggy back }\end{array}$} & \multirow{2}{*}{$\mathrm{TP}$} & 0.5 & 135 & 11 & 0.7 & 0.98 & 5.00 & 47 & 0.7 & 12.5 \\
\hline & & 0.25 & 135 & 12 & 0.7 & 0.78 & 4.35 & 48 & 0.56 & 9.1 \\
\hline \multirow{2}{*}{$\begin{array}{c}\text { Circular } \\
\text { Piggy back }\end{array}$} & \multirow{2}{*}{$\mathrm{CP}$} & 0.5 & 135 & 13 & 0.7 & 0.87 & 4.55 & 49 & 0.68 & 12.5 \\
\hline & & 0.25 & 135 & 14 & 0.7 & 0.67 & 4.00 & 50 & 0.46 & 9.09 \\
\hline \multirow{3}{*}{ Spoiler } & \multirow{3}{*}{ TS } & 1 & 225 & 15 & 0.7 & 0.75 & 4.17 & 51 & 0.64 & 14.3 \\
\hline & & 0.5 & 225 & 16 & 0.7 & 0.88 & 4.76 & 52 & 0.68 & 10 \\
\hline & & 0.25 & 225 & 17 & 0.7 & 0.59 & 4.00 & 53 & 0.48 & 7.14 \\
\hline \multirow{2}{*}{$\begin{array}{l}\text { Triangular } \\
\text { piggy back }\end{array}$} & \multirow{2}{*}{$\mathrm{TP}$} & 0.5 & 225 & 18 & 0.7 & 0.85 & 4.35 & 54 & 0.68 & 10 \\
\hline & & 0.25 & 225 & 19 & 0.7 & 0.57 & 4.00 & 55 & 0.47 & 7.14 \\
\hline Circular & CP & 0.5 & 225 & 20 & 0.7 & 0.83 & 4.35 & 56 & 0.58 & 10 \\
\hline Piggy back & 1 & 0.25 & 225 & 21 & 0.7 & 0.53 & 3.85 & 57 & 0.4 & 7.14 \\
\hline & & 1 & 270 & 22 & 0.7 & 0.27 & 3.57 & 58 & 0.15 & 6.06 \\
\hline Spoiler & TS & 0.5 & 270 & 23 & 0.7 & 0.37 & 3.70 & 59 & 0.26 & 6.9 \\
\hline & & 0.25 & 270 & 24 & 0.7 & 0.55 & 3.85 & 60 & 0.37 & 7.41 \\
\hline Triangular & TP & 0.5 & 270 & 25 & 0.7 & 0.43 & 3.70 & 61 & 0.26 & 6.9 \\
\hline piggy back & TP & 0.25 & 270 & 26 & 0.7 & 0.50 & 3.85 & 62 & 0.35 & 7.41 \\
\hline Circular & CP & 0.5 & 270 & 27 & 0.7 & 0.40 & 3.70 & 63 & 0.29 & 7.41 \\
\hline Piggy back & $\mathrm{CP}$ & 0.25 & 270 & 28 & 0.7 & 0.56 & 3.85 & 64 & 0.40 & 6.9 \\
\hline & & 1 & 90 & 29 & 0.7 & 0.20 & 3.45 & 65 & 0.11 & 5.88 \\
\hline Spoiler & TS & 0.5 & 90 & 30 & 0.7 & 0.33 & 3.57 & 66 & 0.22 & 6.67 \\
\hline & & 0.25 & 90 & 31 & 0.7 & 0.50 & 3.85 & 67 & 0.33 & 7.14 \\
\hline Triangular & TP & 0.5 & 90 & 32 & 0.7 & 0.43 & 3.70 & 68 & 0.21 & 6.67 \\
\hline piggy back & $1 \mathrm{~T}$ & 0.25 & 90 & 33 & 0.7 & 0.55 & 3.85 & 69 & 0.35 & 7.14 \\
\hline Circular & & 0.5 & 90 & 34 & 0.7 & 0.36 & 3.57 & 70 & 0.22 & 6.67 \\
\hline Piggy back & CP & 0.25 & 90 & 35 & 0.7 & 0.54 & 3.85 & 71 & 0.4 & 7.14 \\
\hline Simple pipe & & - & - & 36 & 0.7 & 0.53 & 3.8 & 72 & 0.37 & 6.95 \\
\hline
\end{tabular}

section area perpendicular to the flow and pressure on the upstream of the pipe increases, causing the increase of the piping strength and the bed shear stress under the pipe as compared to simple pipe. In the self-burial pipe mode, by the increasing the bed shear stress and occurrence of piping under the pipe, the pipe moves faster toward the bed and rapidly approaches the equilibrium self-burial depth. As a result, the equilibrium time of the selfburial depth is reduced compared to the simple pipe. However, the equilibrium time of the scour depth increased. With decreasing spoiler and piggy back heights $(h=D / 4)$, although the cross-section area perpendicular to the flow decreases, it increases relative to the simple pipe and the line slope of the scour and self-burial become slightly steeper than that of the simple pipe.

At an angle of $225^{\circ}$, with increasing spoiler and piggy back heights $(h=D$ and $h=D / 2)$, the crosssection area perpendicular to flow at the upstream of the pipe will be similar to the simple pipe, but it increases the cross-section area perpendicular to flow direction at the downstream of the pipe. This position may increase the scouring and self-burial depths and the equilibrium time compared to the simple pipe. However, it decreases the maximum scour and self-burial depths and the line slope as compared with the angles of 180 and $135^{\circ}$. By decreasing the spoiler and piggy back heights $(h=$ $D / 4)$, their effect on scour and self-burial decreases and the line slope is close to the simple pipe (Fig. 7, $\alpha=225^{\circ}$ ).

For the angle of $270^{\circ}$, the cross-section area perpendicular to the flow direction at the upstream of the pipe is similar to that of the simple pipe, however, with increasing spoiler and piggy back heights, the flow path downstream of the pipe is disrupted and the piping phenomenon occurs with delay and less strength. As a result, the expansion rates of the scour and self-burial depths decrease 
considerably compared to the simple pipe, resulting in a mild line slope. In addition, the equilibrium time of the scour and self-burial reduce compared to the simple pipe. By decreasing the spoiler and the piggy back heights $(h=D / 4)$, their effect on the streamlines downstream of the pipe is reduced and the line slope for the equilibrium time of the scour and self-burial are the same as the simple pipe (Fig. $7, \alpha=270^{\circ}$ )

At an angle of $90^{\circ}$, with increasing spoiler and piggy back heights, although the cross section area perpendicular to the flow direction at the upstream of the pipe does not change and is similar to the simple pipe, due to the position of the spoiler and piggy back, the inflow path upstream of the pipe is disrupted and less flow passes below the pipe. As a result, the piping phenomenon occurs with a longer delay and less strength and the expansion rates of the scour and self-burial depths decrease considerably compared to the simple pipe. The equilibrium time of the scour and self-burial reduce compared to the simple pipe. By decreasing the spoiler and the piggy back heights $(h=D / 4)$, their effect on the streamlines upstream of the pipe is reduced and the diagrams for equilibrium scour and self-burial are similar to the simple pipe (Fig. 7, $\alpha=$ $\left.90^{\circ}\right)$.

According to the results obtained, Increasing the line slope reduces the time scale and vice versa. Therefore, the time scale of self-burial is lower than that of the scour. The amount of non-dimensional scale time of scour and self-burial are presented in Table 1.

\subsection{Effect of Spoiler and Piggy back on the Scouring Time Scale}

Figurer 8 shows the scouring time scale for all experimental tests. Eq. (13) to (16) was fitted on the experimental result by using MATHEMATICAL software (Salehi and Azimi 2019) to compare by previous studies such as (Fredsøe and Deigaard 1992), As can it be seen, the simple pipe shows a good agreement with Eq. 2; however, it has a negligible different from Eq. 5 (Zhang et al. 2017). Comparison between experimental tests and literature illustrated that due to increasing the main diameter size of the sediment the equilibrium time shift to the less values which can be indicated in Fig. 8 that the experimental test with larger $d_{50}$ shift to the left side of the vertical axes. As a result, by increasing the main diameter size it can be predicted that the equilibrium time reaches the less values. On the other hand, the results of the changes in external geometry of the pipe show a decrease and an increase in the line slope compared to the simple pipe. Equation 13 has suitable agreement with the experimental data and Eq. 2 (Fig. 9).

$d s=d_{S e}(0.73+0.224(\ln t / T))$

\subsection{Effect of Spoiler and Piggy back on the Self-Burial Time Scale}

Fredsøe and Deigaard (1992) found that the selfburial and scouring time scales are similar and follow a same relationship. Figure 10 shows the self-burial time scale for all experimental tests. Furthermore, Eq. (14) was proposed based on experimental tests results due to comparing by scouring time scales once the pipe is free at the bottom. Comparison between scour and self-burial tests illustrate the self-burial process reaches equilibrium condition due the less time duration (Fig. 10). It assumes this condition is deduced from flow hydrodynamic configuration. In order to investigate this matter, Fig. 12 were plotted based on numerical models to compare the flow configuration of self-burial and scour hole together. Moreover, Fig. 11 shows that the proposed equation (Eq. 14) has suitable agreement by experimental tests. Although the trend of the self-burial and scouring time scales are similar, due to the occurrence of piping phenomenon in simple pipe, the slope of the self-burial diagram becomes steeper than the scour diagram.

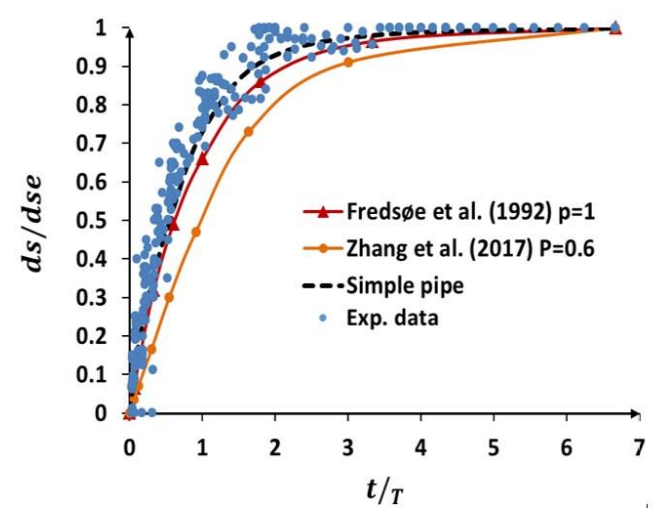

Fig. 8. Scouring time scale in all states.

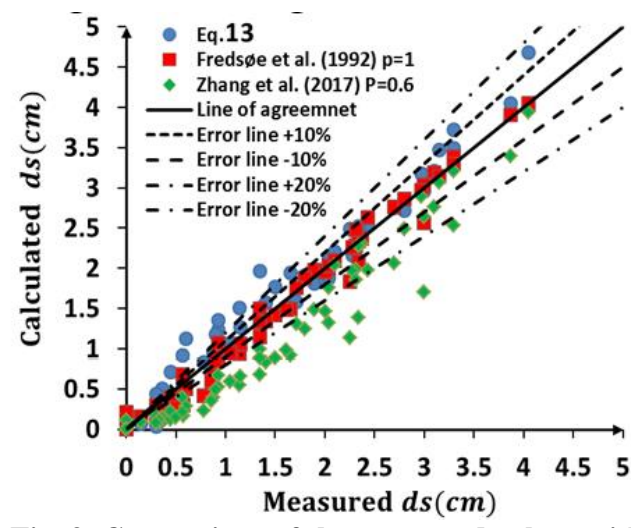

Fig. 9. Comparison of the measured values with Eqs. 2, 5, and 13.

$d s^{*}=d_{S e}^{*}\left(0.7+0.186 \ln \left(t / T^{*}\right)\right)$

Figure 12 show the streamwise velocity for selfburial and scour hole. Figure 12a illustrates that due to equilibrium scour hole, the region behind the pipeline in self-burial process turned to the two oriental jets which one of the jets developed at the top the pipeline and another was flown at the bottom of the pipeline. However, the self-burial process because of unsegment situation did not 


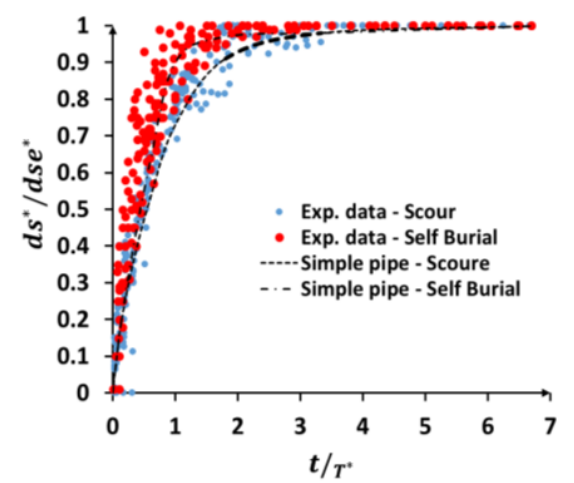

Fig. 10. Scouring and self-burial time scales in all states.

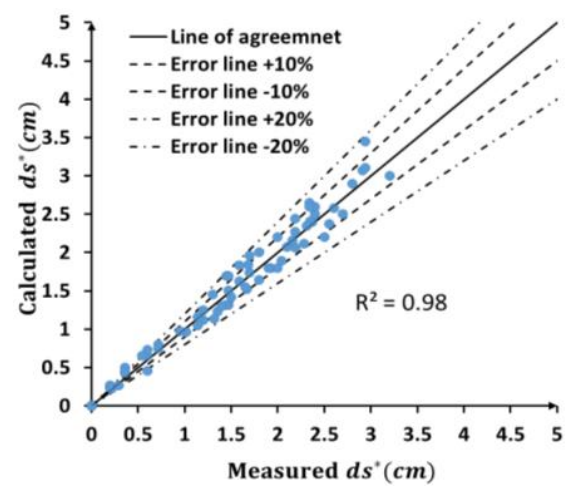

Fig. 11. Comparison of measured values with Eq. 14 in all states.

a)

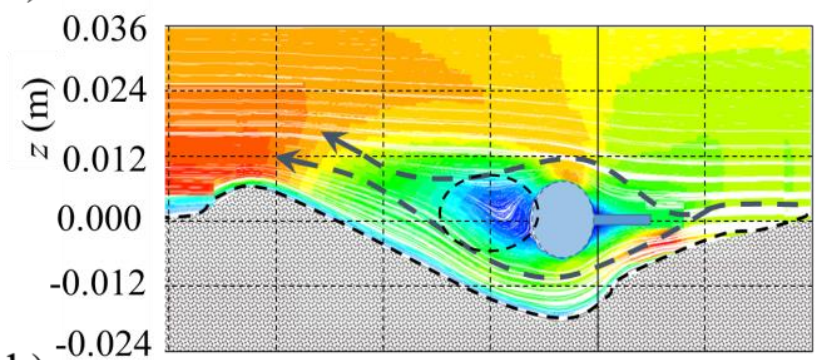

b) 0.036

(1)

0.024
$\widehat{\Xi}_{\mathrm{N}}^{0.012}$
0.000
-0.012
-0.024
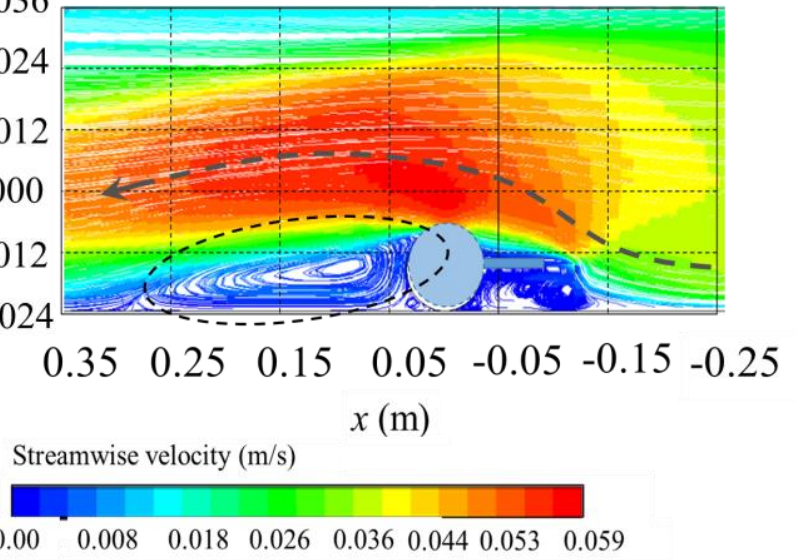

Fig. 12. Comparision between developted flows through the self-buril and scour process ,a)scour bed; b) self-burial.

allow to develop a jet under the pipe position. By buried the pipe, the sediment volume accumulates at the top of the pipeline; meanwhile, it is assumed the equilibrium condition into the scour hole condition (fix pipe) take much time because of two jet impact occurrences at the downstream of pipe line. Consequently, equilibrium time in self-burial condition is less that the one. As a result, the experimental results of self-burial into the Fig. 10 shift to the less values (left hand on the horizontal axes) than the scour hole condition.

\subsection{Effect of Spoiler and Piggy back on the Lee Erosion}

Figure 13 shows the changes in the bed profile of the scouring and self-burial of the simple pipe over time. As can be seen in Fig. 13, with increasing the time, the characteristics of the scour profile, such as the maximum depth and length of the lee erosion on downstream and upstream of the pipe, are gradually developed to reach equilibrium. However, the characteristics of the self-burial profile do not change significantly. The reason for this can be attributed to the lack of tunnel erosion in the selfburial of the pipe. In the first moments of the experiment, the lee erosion length increases over time, but after reaching the equilibrium scour and self-burial depths, the lee erosion length rate gradually decreases. Some researches confirm this matter as (Sumer and Fredsøe 1992; Chiew 1990 which it result has been illustrated as Fig. 14 and $15)$. 
a)

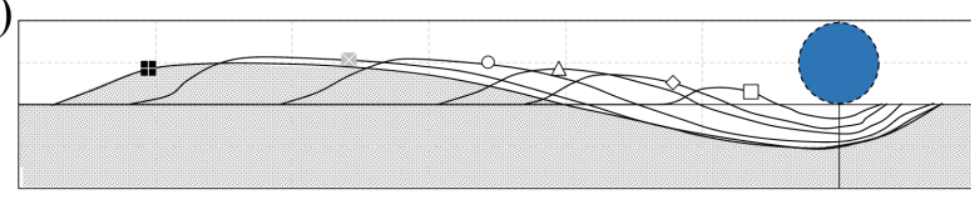

b)

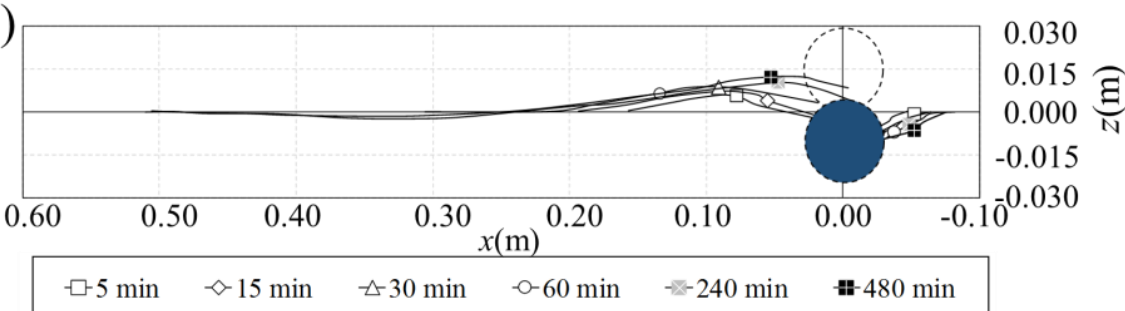

Fig. 13. Stages of development of bed profiles over time, a) scour hole bed; b) self-burial.

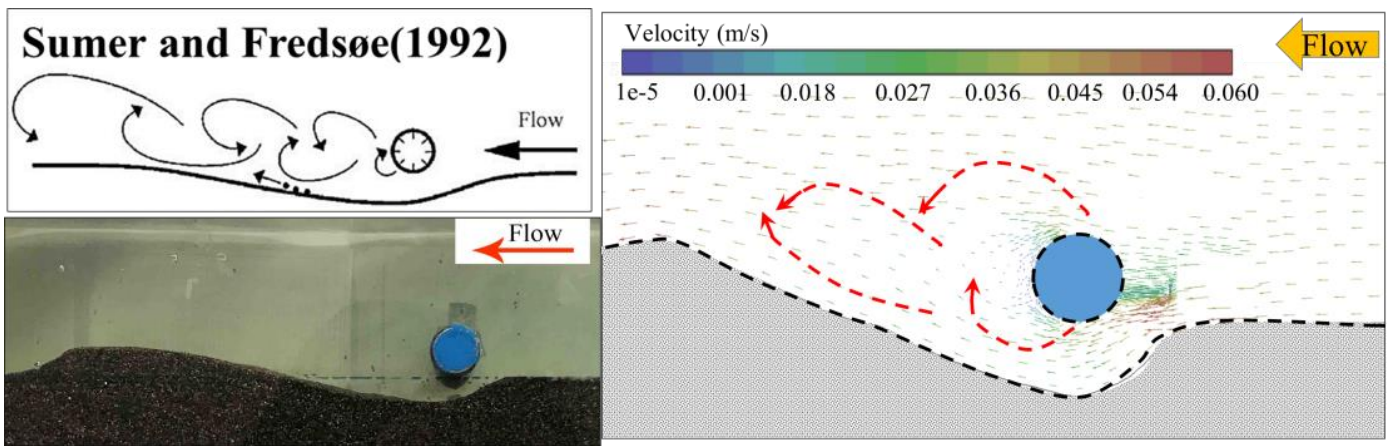

Fig. 14. The final profile of the scour bed.
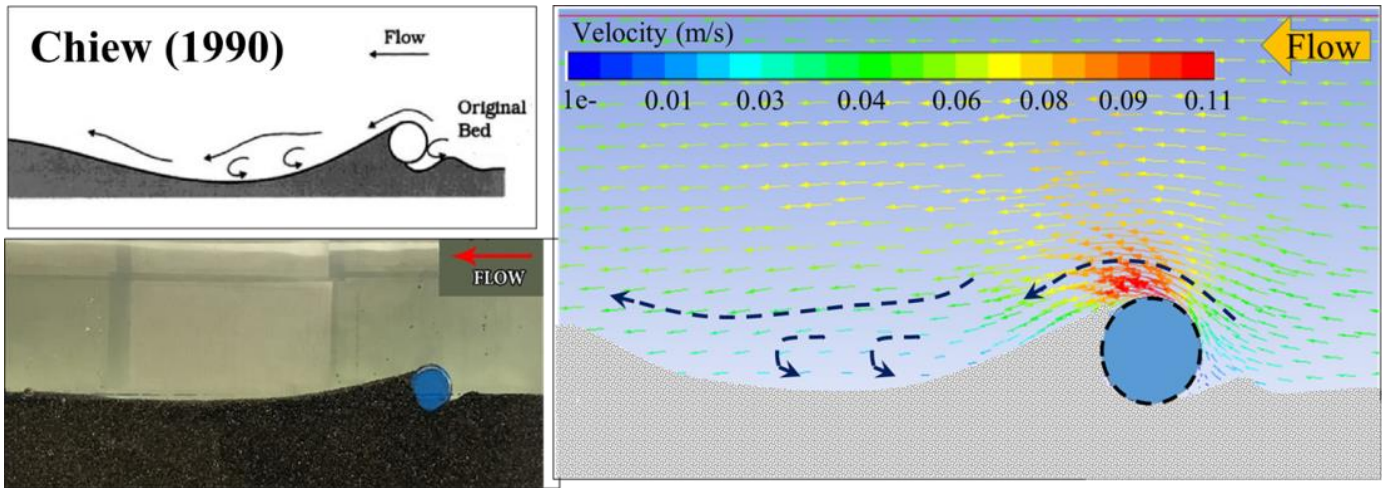

Fig. 15. Final profile of the self-burial bed.

In order to investigate the length of the lee erosion, Fig. 16 shows the final profiles of the scour and self-burial bed of the simple pipe and the pipe with spoiler and piggy back. In addition, Table 2 presents the length of the lee erosion in terms of pipe diameter for the scour and self-burial of the simple pipe and pipe with spoiler and piggy back. According to Table 2, the length of the lee erosion, for the simple pipe and for the scour and self-burial beds are $12 D$ and $10 D$, respectively, which shows an increase in the lee erosion in the scour relative to the self-burial. The results of Fig. 16 and Table 2 show that the lee erosion length depends on the shape of the spoiler and the piggy back, their angles and heights. So that at 180 and $135^{\circ}$, with increasing the spoiler and piggy back heights, lee erosion length of the scour and self-burial increase compared with the simple pipe. Furthermore, the results also showed that the lee erosion length for spoiler and triangular piggy back is higher than the circular piggy back. Also, at angles of 225, 270 and $90^{\circ}$ with increasing spoiler and piggy back heights, the lee erosion of the scour and self-burial decrease compared to simple pipe, among them, the spoiler has the highest decrease. In general, the changes in length of the lee erosion due to changes in the 
M. Damroudi et al. / JAFM, Vol. 14, No. 1, pp. 103-115, 2021.

Table 2 Effect of Spoiler and Piggy back on the lee erosion of the Scour and Self-burial bed (in terms of D).

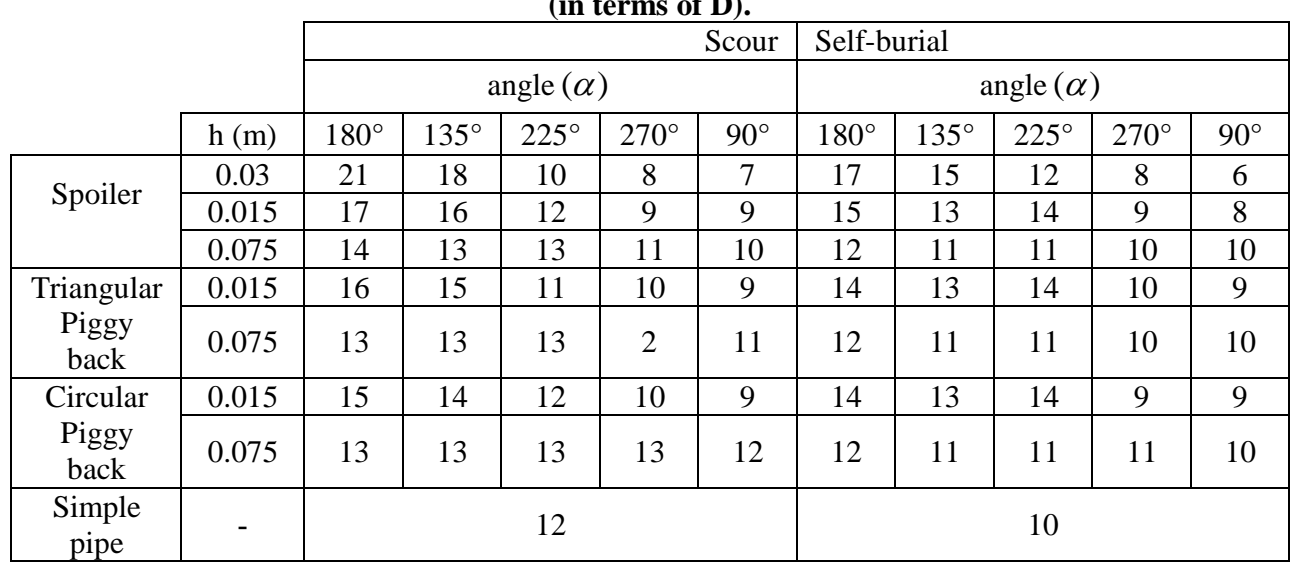
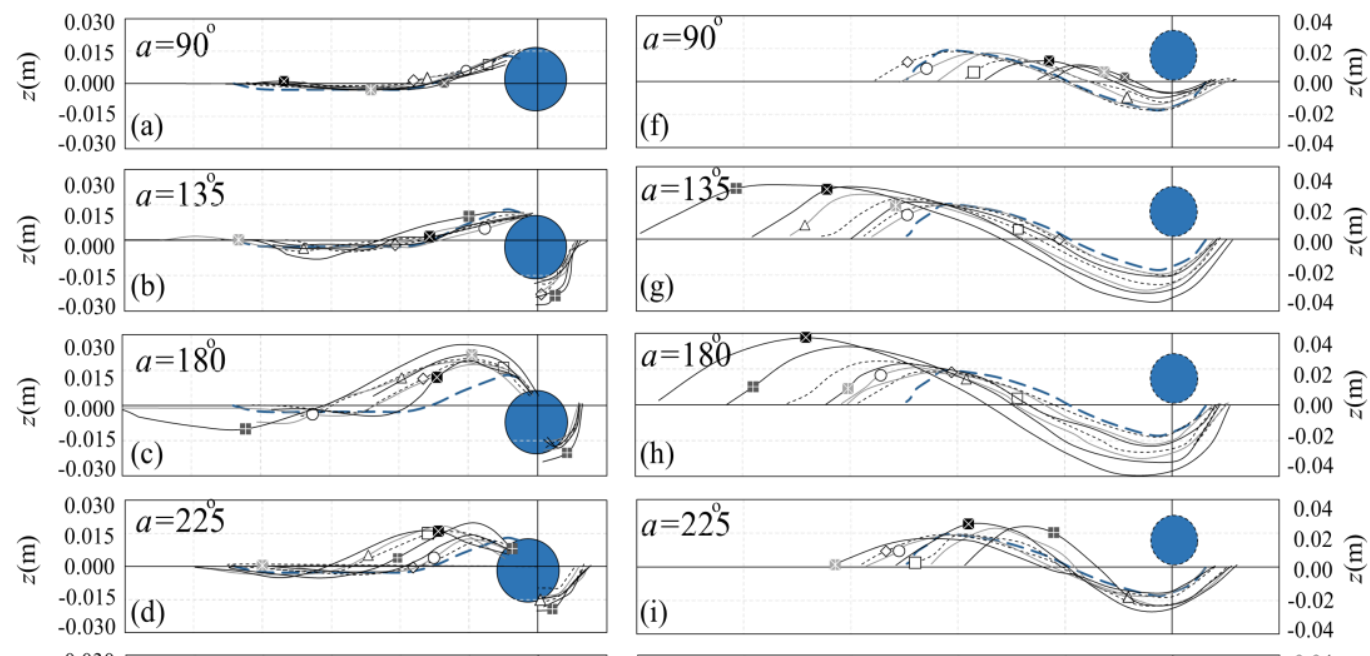

(h)
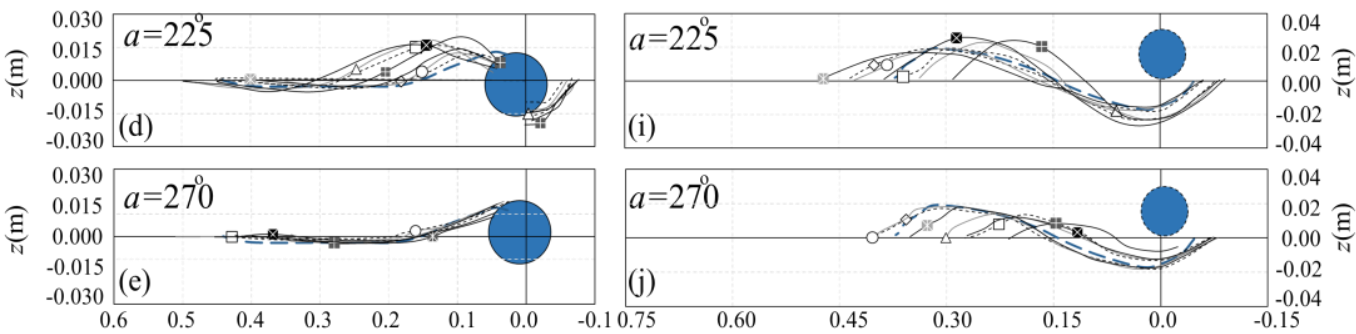

\begin{tabular}{|c|c|c|}
\hline - Non & $\square \mathrm{CP}, S=15 \mathrm{~mm}$ & $\diamond \mathrm{CP}, S=7.5 \mathrm{~mm}$ \\
\hline$\triangle \mathrm{TP}, S=15 \mathrm{~mm}$ & - ТP, $S=7.5 \mathrm{~mm}$ & $\star \mathrm{RS}, S=30 \mathrm{~mm}$ \\
\hline$-\mathrm{RS}, S=15 \mathrm{~mm}$ & $-20-\mathrm{RS}, S=7.5 \mathrm{~mm}$ & \\
\hline
\end{tabular}

Fig. 16. Scour bed and self-burial bed Profile, a) Self-burial $\left(a=90^{\circ}\right)$; b) Self-burial $\left(a=135^{\circ}\right)$; c) Selfburial $\left(a=180^{\circ}\right)$; d) Self-burial $\left(a=225^{\circ}\right)$; e) Self-burial $\left(a=270^{\circ}\right)$; f) Scour bed $\left(a=90^{\circ}\right)$; $)$ Scour bed $\left(a=135^{\circ}\right)$; h) Scour bed $\left(a=180^{\circ}\right)$; i) Scour bed $\left.\left(a=225^{\circ}\right) ; j\right)$ Scour bed $\left(a=270^{\circ}\right)$.

external geometry of the pipe are in the range of $7 D$ $\leq X \leq 20 D$ for the scour hole and $6 D \leq X \leq 17 D$ for the self-burial hole, indicating a decrease in the lee erosion length in the self-burial state.

\subsection{Cour BED and Sele-Burial}

The Eqs. 15 and 16 are developed for the scour and self-burial depths, respectively (angles are in radians) that can be used for scour and self-burial depths of pipe with spoiler or piggy back in different angles. The comparison between the measured scour and self-burial depths and those computed from Eqs. 15 and 16, are given in Fig. 17 and 18 , respectively.
Scatter index $(S I)$ were employed to check the accuracy of the proposed equations. As shown in this figures, the measured and computed scour and self-burial depths are in good agreement.

$$
\begin{aligned}
& \frac{d s}{D}=-0.5\left(\frac{t}{T}\right)^{0.3}+0.59\left(\frac{L s}{D}\right)^{0.5}+4.28\left(\frac{h}{D}\right)^{0.02} \\
& -0.04(\alpha)^{0.4}-4.7
\end{aligned}
$$

$\frac{d s^{*}}{D}=0.26\left(\frac{t}{T}\right)^{0.3}+0.43\left(\frac{L_{S}^{*}}{D}\right)^{0.5}-0.13\left(\frac{h}{D}\right)^{0.02}$

$-0.11(\alpha) 0.4-1.16$ 


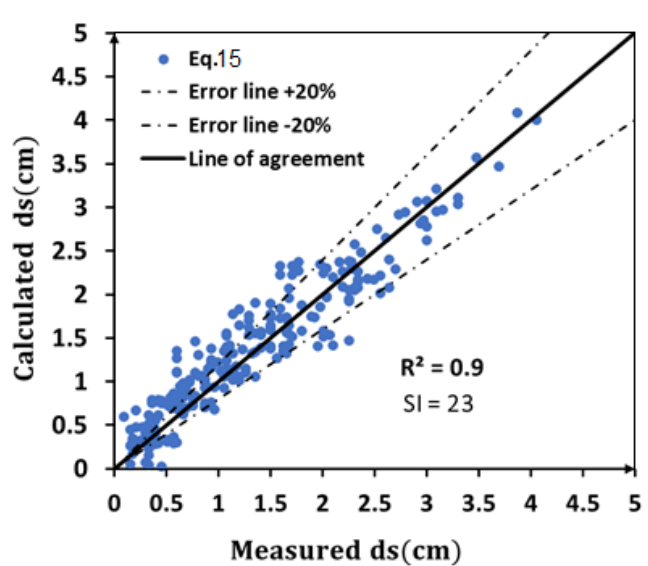

Fig. 17. Comparison of the Results of the Scour with Eq. 14.

\section{Conclusion}

In this study, the effect of pipe external geometry on local scour and self-burial time scales and flow pattern has been experimentally investigated. The summary of conclusions can be found as follows:

- The tunnel erosion and the re-occurrence of the piping, respectively, play an important role in increasing the scour and self-burial depths.

- Due to changes in the scour and self-burial processes, the final profile of the scour and selfburial beds is different. In addition, the spoiler and Piggy back angles cause changes the final profile of the self-burial bed, however, have no effect on the final scour profile.

- The equilibrium time of the scour and selfburial depends on the height, the shape of the spoiler and Piggy back, and their angles. Therefore, the determination of the optimum position will be of great help in the design and stabilizing the pipe.

- The time scale of self-burial process is lower than the time scale of scour process.

- Scour and self-burial rates depend on Piggy the height, angle, shape of the spoiler and back, so that at 180,135 and $225^{\circ}$ angles, the scour and self-burial rates constitute 80 and 91 percent, respectively, compared to the simple pipe.

- The length of the lee erosion of the scour is more than that of the self-burial by $2 \mathrm{D}$ (for simple pipe). By the attaching the spoiler or piggy back on the pipe at 180 and $135^{\circ}$ angles, the lee erosion for scour and self-burial increase by $6 \mathrm{D}$ and $4 \mathrm{D}$, respectively, compared to the simple pipe. At angles of 270 and $90^{\circ}$, in addition to reducing the maximum scour and self-burial depth, the lee erosion length is reduced relative to the simple pipe.

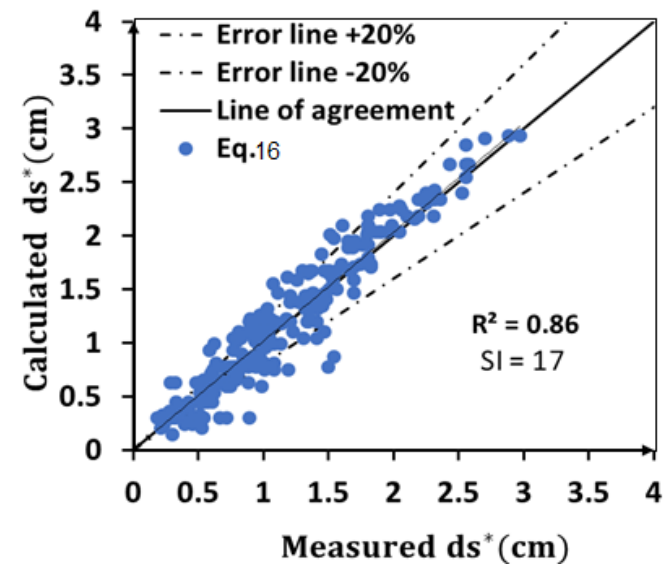

Fig. 18. Comparison of the Results of the self-burial with Eq. 15.

\section{REFERENCES}

Abbasi, S., M. Masoomi and S. A. Arjmandi, (2018). Impact of a Single Spoiler on Scouring Depth Status Beneath a River Crossing Inclined Pipeline. Engineering, Technology \& Applied Science Research 8(5), 3316-3320.

Bearman, P. W. and M. M. Zdravkovich (1978). Flow around a circular cylinder near a plane boundary. Journal of Fluid Mechanics 89(1), $33-47$.

Breusers, H., \& Raudkivi, A. J. (1991). Scouring. Hydraulic structures design manual series. IAHR Design Manual.

Brankovic', M., Zeitoun, H., Sutherland, J., Pearce, A., Jacobsen, V., Sabavala, H., ... \& Willcocks, J. (2010). Physical modelling of hydrodynamic loads on piggyback pipelines in combined wave and current conditions. In International Conference on Offshore Mechanics and Arctic Engineering. 49132(933-942).

Cheng, L. and L. W. Chew (2003). Modelling of flow around a near-bed pipeline with a spoiler. Ocean Engineering 30(13), 15951611.

Chiew, Y. M. (1990). Mechanics of local scour around submarine pipelines. Journal of Hydraulic Engineering 116(4), 515-529.

Dey, S. and A. K. Barbhuiya (2004). Clear-water scour at abutments in thinly armored beds. Journal of Hydraulic Engineering 130(7), 622-634.

Draper, S., H. An, L. Cheng, D. J. White and T. Griffiths (2015). Stability of subsea pipelines during large storms. Philosophical Transactions of the Royal Society A: Mathematical, Physical and Engineering Sciences 373(2033), 20140106. 
Fredsoe, J., B. M. Sumer and M. M. Arnskov (1991, January). Time scale for wave/current scour below pipelines. In The First International Offshore and Polar Engineering Conference. International Society of Offshore and Polar Engineers.

Guan, D., B. W. Melville and H. Friedrich (2014). Flow patterns and turbulence structures in a scour hole downstream of a submerged weir ASCE, Journal of Hydraulic Engineering 140(1), 68-76.

Guan, D., B. W. Melville and H. Friedrich (2015). Live-Bed Scour at Submerged Weirs. Journal of Hydraulic Engineering 141(2), 0401407112 .

Huisbergen, C. H. (1984, January). Stimulated self-burial of submarine pipelines. In Offshore Technology Conference. Offshore Technology Conference.

Hulsbergen, C. H. (1986, January). Spoilers for stimulated self-burial of submarine pipelines. In Offshore technology conference. Huston. Texas. USA.

Hulsbergen, C. H., \& Bijker, R. (1989, January). Effect of spoilers on submarine pipeline stability. In Offshore technology conference. Huston. Texas. USA.

Lee, W. D., H. J. Jo, H. S. Kim, M. J. Kang, K. H. Jung and D. S. Hur. (2019). Experimental and numerical investigation of self-burial mechanism of pipeline with spoiler under steady flow conditions. Journal of Marine Science and Engineering 7, 456

Melville, B. W. (1997). Pier and abutment scour: integrated approach. Journal of Hydraulic Engineering 123(2), 125-136.

Melville, B. W. and A. J. Sutherland (1988). Design method for local scour at bridge piers. Journal of Hydraulic Engineering 114(10), 1210-1226.

Melville, H. (1984). The confidence-man: his masquerade (Vol. 10). Northwestern University Press.

Öner, A. A. (2016). Numerical investigation of flow around a pipeline with a spoiler near a rigid bed. Advances in Mechanical Engineering 8(6), 1687814016651794.

Salaheldin, T. M., J. Imran and M. H. Chaudhry (2004). Numerical modeling of threedimensional flow field around circular piers. Journal of Hydraulic Engineering 130(2), 91-100.

Salehi, S. and A. H. Azimi (2019). Discharge Characteristics of Weir-Orifice and Weir-Gate Structures. Journal of Irrigation and Drainage Engineering 145(11), 04019025.

Salehi, S., K. Esmaili and A. H. Azimi (2019). Mean velocity and turbulent characteristics of flow over half-cycle cosine sharp-crested weirs. Flow Measurement and Instrumentation 66, 99-110.

Shan, D., Y. Liu and Y. Li (2015). Numerical Simulation of Submarine Pipeline Self-Buried on Sediment Seabed. Advances in Petroleum Exploration and Development 10(1), 44-50.

Sumer, B. M., \& Fredsøe, J. (1997). Scour at the head of a vertical-wall breakwater. Coastal Engineering, 29(3-4), 201-230.

Sumer, B. M. (2006). Hydrodynamics around cylindrical strucures (Vol. 26). World scientific.

Whitehouse, R. (1998). Scour at marine structures: A manual for practical applications. Thomas Telford.

Yang, L., B. Shi, Y. Guo and X. Wen (2012). Calculation and experiment on scour depth for submarine pipeline with a spoiler. Ocean Engineering 55, 191-198.

Zang, Z. P., F. P. Gao and J. S. Cui (2013). Physical modeling and swirling strength analysis of vortex shedding from near-bed piggy back pipelines. Applied Ocean Research 40, 50-59.

Zeitoun, H., M. Brankovic', K. Tornes, S. Wong, E. Hollingsworth, A. Pearce and H. Sabavala (2010, January). Dynamic stability response of piggy back pipelines. In International Conference on Offshore Mechanics and Arctic Engineering 49132 ,731-739.

Zhang, J., B. Shi, Y. Guo, W. Xu, K. Yang and E. Zhao (2016). Scour development around submarine pipelines due to current based on the maximum entropy theory. Journal of Ocean University of China 15(5), 841-846.

Zhang, Q., S. Draper, L. Cheng and H. An (2017). Time scale of local scour around pipelines in current, waves, and combined waves and current. Journal of Hydraulic Engineering 143(4), 04016093.

Zhao, E., S. Bing, Q. Qu Ke, D. Dong Wenbin and Z. Jing (2018). Experimental and Numerical Investigation of Local Scour around Submarine Piggy back Pipeline under Steady Current. Journal of Ocean Univ. China (Oceanic and Coastal Sea Research 17(2), 244-256.

Zhao, J. and X. Wang (2009). CFD numerical simulation of the submarine pipeline with a spoiler. Journal of Offshore Mechanics and Arctic Engineering 131(3).

Zhao, M., L. Cheng and B. Teng (2007). Numerical modeling of flow and hydrodynamic forces around a piggy back pipeline near the seabed. Journal of Waterway, Port, Coastal, and Ocean Engineering 133(4), 286-295. 